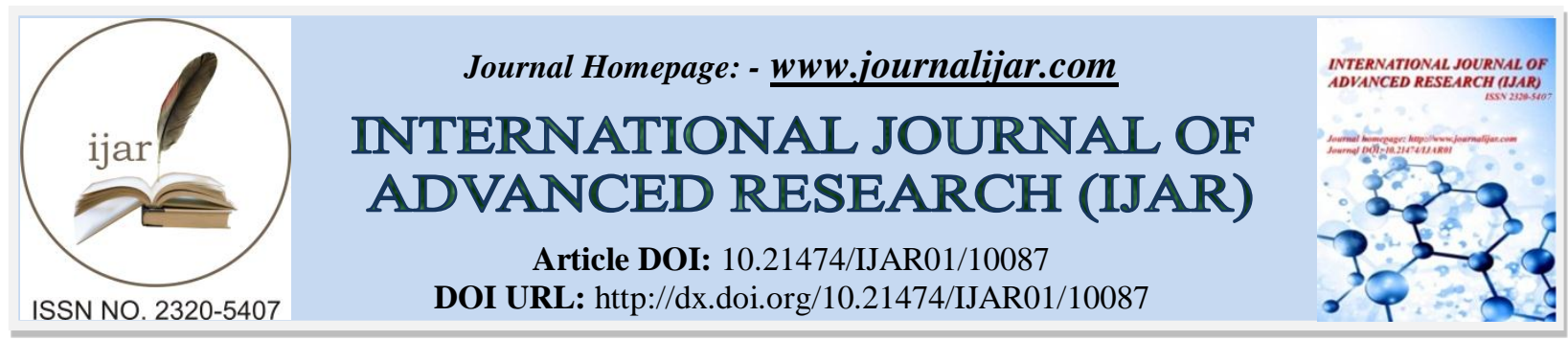

RESEARCH ARTICLE

\title{
SCAPULA LANGERHANS CELL HISTIOCYTOSIS IN A CHILD : A CASE REPORT.
}

\author{
S. El Haddad ${ }^{1}$, L. Hessissen ${ }^{2}$, N. Allali ${ }^{1}$ and L. Chat ${ }^{1}$.
}

1. Pediatric imaging departement, Pediatric teaching hospital-Rabat-Morroco.

2. Pediatric oncology departement,Pediatric teaching hospital-Rabat-Morroco.

\section{Manuscript Info}

Manuscript History

Received: 14 September 2019

Final Accepted: 16 October 2019

Published: November 2019

Key words:-

MRI, scapula, child, LCH.

\begin{abstract}
Langerhans cell histiocytosis ( $\mathrm{LCH})$ is a proliferative histiocytic disorder relativily rare in the perdiatric group. This complex disease has no specific clinical or radiographic presentation. The scapula is one of the rarest site of LCH. Imaging and specially MRI are particularly helpful for characterizing the lesion and delineating the local and systemic extent. In this report, we present a rare case of Langerhans cell histiocytosis of the scapula in a 07 month-old baby.
\end{abstract}

Copy Right, IJAR, 2019,. All rights reserved.

\section{Introduction:-}

Langerhans cell histiocytosis ( $\mathrm{LCH})$ is primarily a disease of childhood . It affect predominantly a population between 5 and 15 years with an average age of 10-14 years.(1,2) The disease course has a spectrum from spontaneous resolution to progressive multisystem disorder. The lesions share the common histology of CD1a+/CD207+ dendritic cells. Radiography remains important in the diagnostic and staging procedure of bone lesion. Computed tomography (CT) or magnetic resonance imaging (MRI) may be necessary to assess precisely the degree of cortical bone destruction or to assess the degree of soft tissue infiltration. $(3,4)$.

\section{Case report:}

A 07 month-old baby was reported with 02 month history of progressive pain in the right shoulder and restriction of movements. No fever, chills, night sweats or weight loss, were seen. The patient received analgesics on and off for 01 month and again complained of pain and presents a shoulder swelling with volume increase. X-RAY showed illdefined osteolytic lesion without sclerotic margin in both scapula with cortical blow (Figure 1). MRI demonstrate an heterogeneous hyperintense signals involving the scapula on STIR and T2 weighted images, with enhancement after gadolinium-based contrast agent administration (figure 2). An associated large extraosseus soft tissue component was seen. CT scan demonstrates a geographic osteolytic lesion with subtle areas of marginal sclerosis. Biopsy taken from the bony lesion showed a lesion composed of sheets of histiocytes.

\section{Discussion:-}

Langerhans cell histiocytosis $(\mathrm{LCH})$ is a rare disease, divided into three groups on the basis of the number of lesions and systems involved. $(2,7)$

In the year 1868, Paul Langerhans discovered the epidermal dendritic cells.However, the Birbeck granule was not identified until the 1970s by Nezelof.(1) 
Diagnosis of LCH is made by corroborating clinical features, histopathology, immunohistochemistry, and radiologic findings. No specific clinical and radiographic presentation of LCH is described in the literature.

LCH may present as a single bone lesion, skin rash, or as invasive disseminated disease and occurs typically in the pediatric and adolescent population, affecting both males and females. $(1,2,8,6)$

Although long bone involvement is more common in children, isolated flat bone involvement is more commonly seen in adults and is consistent with the case report findings described above. The scapula is the site of $3 \%$ of bone tumours, while for LCH it is the least common site. $(1,2)$

The radiographic appearance of the lesions depends on the site of involvement and the phase of the disease. Bone involvement usually presents as a single or multiple osteolytic lesions, with a sclerotic rim and surrounding sclerosis. This is concordant with the CT scan findings of our patient. On MRI, a focal lesion with extensive soft tissue and marrow edema is most commonly found as hypointese areas in T1W images and hyperintense area on T2W and STIR images with enhancement, also consistent with findings in our case report.(3,5,6). An endosteal rim of low signal intensity can be found in LCH, which may be an early sign of healing.

The peritumoral edema is less extensive than that of Ewing's sarcoma and osteomyelitis, two most common differentials of LCH.. $(5,8)$

Bone scintigraphy may be a complementary technique to the radiographic skeletal but its sensitivity is limited. Recently, new imaging techniques, such as positron emission tomographycomputed tomography (PET-CT) and whole-body MRI, have developed in view of an improved assessment of the extent and severity of the disease $(3,7)$, The differential diagnostic considerations including metastasis, plasmacytoma, unicameral and aneurysmal bone cysts, and chondromyxoid fibroma among other disease processes $(1,4)$

The treatment of Langerhans cell histiocytosis (LCH) is still controversial and has changed over the past decades. With advances in pathogenesis, the trend now is towards radiation therapy and cytotoxic chemotherapy. (2)

\section{Conclusion:-}

Langerhans cell histiocytosis (LCH) is a rare disorder, mostly affecting children. The scapula is uncommonly affected in young children. Imaging specially MRI is presently the most informative imaging tool in the management of bone LCH.

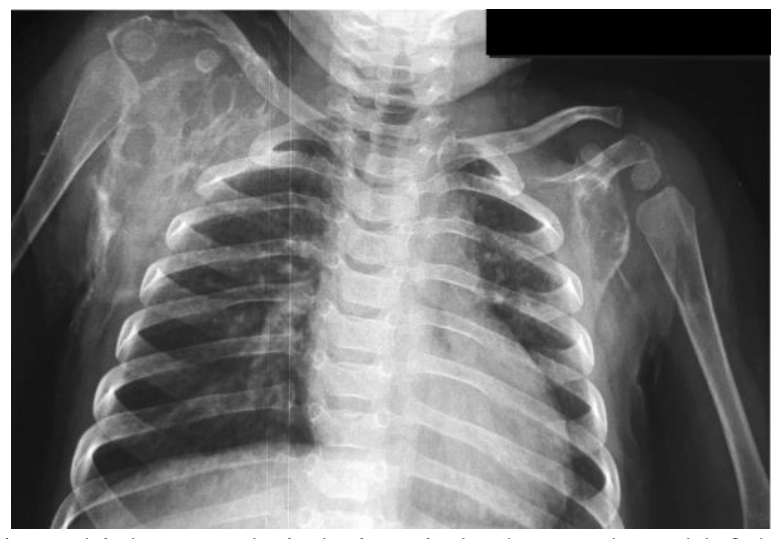

Figure1:-multiples osteolytic lesions in both scapula and left humerus. 

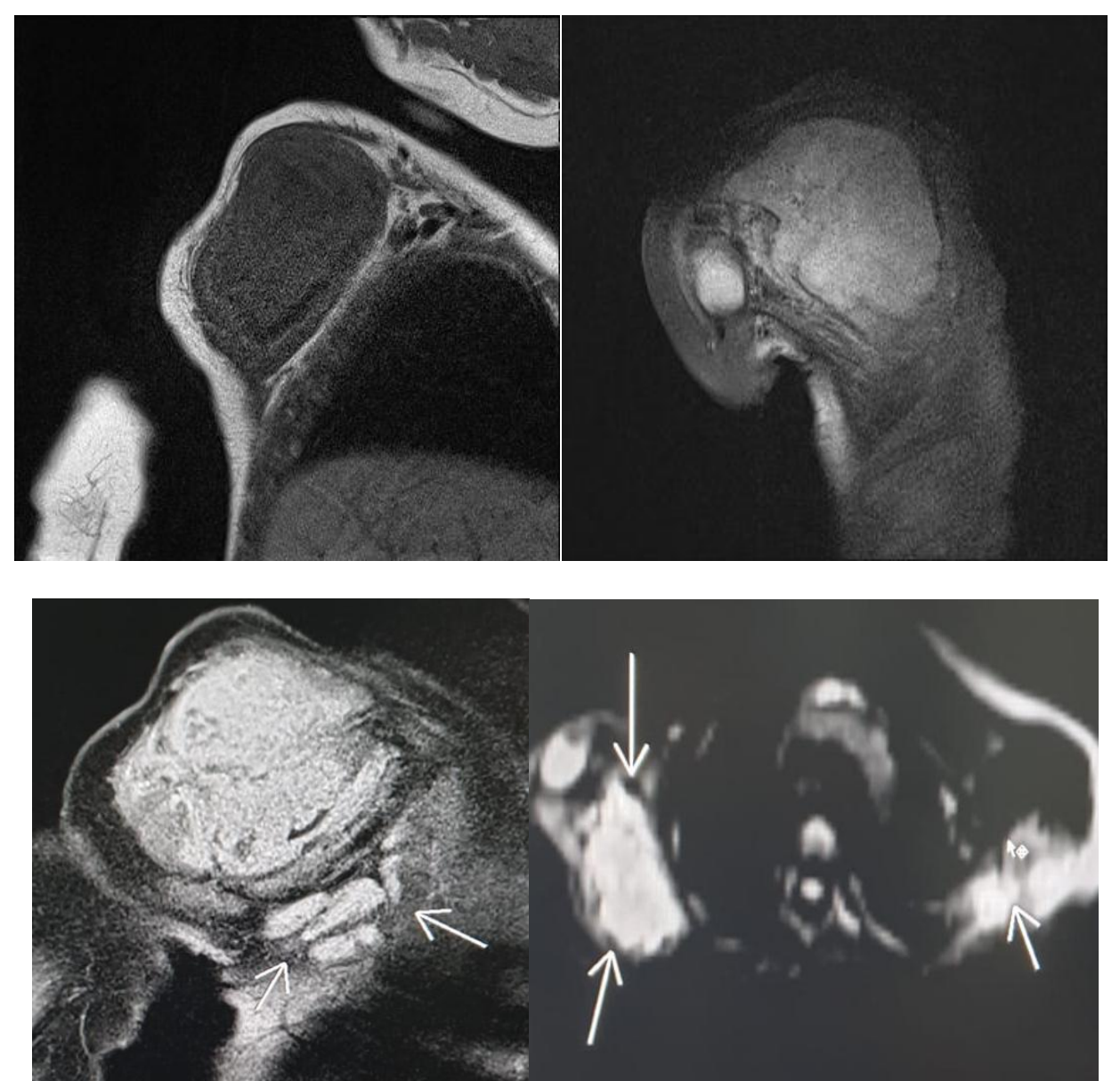

Figure 2:-MRI showed heterogeneous hypointense T1 hyperintense on diffusion and T2 weighted images. Heterogeonous enhancement (arrow). Lymphadenopathy was also noted in right axillary region.

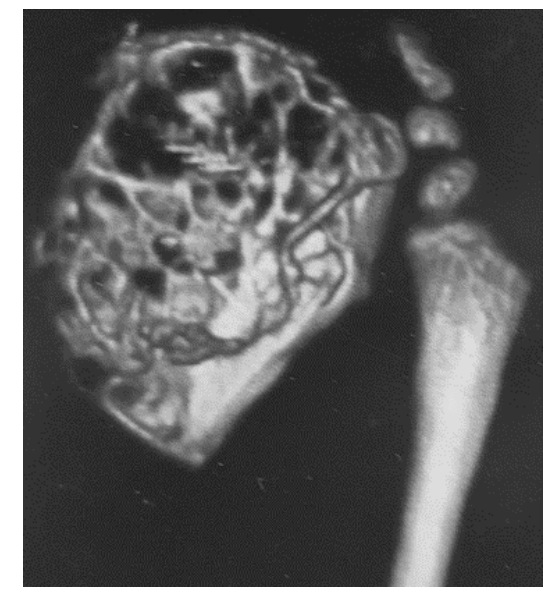

Figure 3:-3D CT image showd multiples lytic lesions

\section{Bibliography:-}

1. Zachary Christopher MDa, Odion Binitie MDb, Evita Henderson-Jackson MDb, Joseph Perno MD, PhDc, Rikesh J. Makanji MDb .Langerhans cell histiocytosis of bone in an adult: A case report.Radiolo Case Rep. 2018 Apr; 13(2): 310-314. Published online 2018 Jan 28.Doi:10.1016/j.radcr.2017.11.020

2. Rohit Pandey1, himanshu Bhayana1, Rajesh KumaR Rajneesh1, ish KumaR dhammi1, Rehan ul-haq1, anil KumaR jain1. LANGERHANS CELL HISTIOCYTOSIS OF THE SCAPULA - DIAGNOSIS \& 
TREATMENT OPTIONS.1808-1851 on-line version ISSN 2177-014XColuna/Columnavol.16no.3Sao Paulo July/Sept.2017 dx.doi.org/10.1590/s1808-18512017161603173214

3. 2. Suonita Khung \& Jean-François Budzik \& Elisa Amzallag-Bellenger \& Anne Lambilliote \& Gustavo Soto Ares \& Anne Cotten \& Nathalie Boutr. Skeletal involvement in Langerhans cell histiocytosis. Insights Imaging (2013) 4:569-579 DOI 10.1007/s13244-013-0271-7

4. 3. GeorgiosTsirakis,MariaKaparou,PeggyKanellou, GeorgiosKontakis,MichaelAlexandraki. Langerhans cell histiocytosis in the right scapula in a young man. Doi :10.5348/ijcri-2012-01-83-CR-5

5. Hashmi MA ${ }^{1}$, Haque N, Chatterjee A, Guha S.Langerhans cell histiocytosis of long bones: MR imaging and complete follow up study. J Cancer Res Ther. 2012 Apr-Jun;8(2):286-8. doi: 10.4103/0973-1482.98991.

6. Shaowu Wang, MD, PhD, Weisheng Zhang, MD, PhD, Shengbo Na, MD, Lina Zhang, MD, and Zhijin Lang, M.Langerhans Cell Histiocytosis of the Clavicle A Case Report and Review of the Literature. Medicine (Baltimore). 2014 Oct; 93(20): e117. Published online 2014 Oct 24. doi: 10.1097/MD.0000000000000117

7. Karima Atarraf1,\&, Lamiae Chater1, Mounir Arroud1, My Abderrahman Afifi.Localisations particulières de l'histiocytose langerhansienne chez l'enfant, scapula et pubis: à propos de deux cas. Panafricain médical journal Received: 23/07/2013 - Accepted: 13/08/2014 - Published: 25/08/2014

8. Jatin Zaveri, MD Quan La, MD Gail Yarmish, MD Jeremy Neuman, MD. More than Just Langerhans Cell Histiocytosis: A Radiologic Review of Histiocytic Disorders1. RadioGraphics 2014; 34:2008-2024 Published online 10.1148/rg.347130132. 